\title{
Heliocotyle ewingi sp. n. (Monogenea: Monocotylidae) from the gills of Myliobatis australis (Myliobatididae) from Tasmania, Australia
}

\author{
Leslie A. Chisholm and Ian D. Whittington
}

Department of Microbiology and Parasitology, The University of Queensland, Brisbane, Queensland 4072, Australia

Key words: Monogenea, Monocotylidae, Heterocotylinae, Heliocotyle ewingi, Myliobatididae, Myliobatis australis, Australia

\begin{abstract}
Heliocotyle ewingi sp. n. (Monogenea: Monocotylidae) is described from the gills of Myliobatis australis Macleay, 1881 (Myliobatididae) collected from Norfolk Bay near Hobart, Tasmania, Australia. Heliocotyle ewingi can be distinguished readily from the only other species in the genus, Heliocotyle kartasi Neifar, Euzet et Ben Hassine, 1999, by the presence of a single pseudoseptum on each of the peripheral loculi except the posteriormost, eyespots and by the morphology of the male copulatory organ which is a short, straight sclerotised tube which lacks a sclerotised accessory piece. The generic diagnosis is revised to accommodate the new species and the anterior glands are discussed.
\end{abstract}

Heliocotyle was proposed recently (see Neifar et al. 1999) to accommodate a monocotylid found on the gills of the myliobatid ray Pteromylaeus bovinus (E. Geoffroy St. Hilaire, 1817) off the coast of Tunisia. The genus was characterised by the haptor which possesses seven peripheral loculi, which all, except the posteriormost, are further divided by pseudosepta and by the presence of a single accessory structure on the dorsal surface of the haptor. Neifar et al. (1999) placed this genus in the Heterocotylinae Chisholm, Wheeler et Beverley-Burton, 1995. We collected a single specimen of Myliobatis australis Macleay, 1881 (Myliobatididae) from Tasmania and found a monocotylid on the gills which we have identified as a new species of Heliocotyle. We revise the generic diagnosis to accommodate the new species.

\section{MATERIALS AND METHODS}

A single specimen of Myliobatis australis Macleay, 1881 was collected by gill net in Norfolk Bay, near Hobart Tasmania in January, 1997. The ray was identified from Last and Stevens (1994) and was killed by pithing. Each gill arch was excised, placed in a Petri dish of filtered seawater (FSW; fresh seawater was filtered through a $0.22 \mu \mathrm{m}$ disposable Millipore filter) and examined under a stereomicroscope using incident light. The microhabitat of live monogeneans was noted, after which they were removed from the gill lamellae and transferred to dishes containing FSW. Monogeneans were fixed either flattened under coverslip pressure in $10 \%$ buffered neutral formalin (BNF) at room temperature or unflattened in $10 \% \mathrm{BNF}$ at room temperature after immersion in boiling seawater. Some flattened specimens were stained with Semichon's carmine or left unstained. All flattened specimens were dehydrated in an ethanol series, cleared in cedarwood oil and mounted in Canada balsam.
Some unflattened specimens were processed for scanning electron microscopy (SEM). Specimens were post-fixed in $1 \%$ osmium tetroxide in $0.1 \mathrm{M}$ buffer for $2 \mathrm{~h}$ and dehydrated in a graded ethanol series. Specimens were dried by soaking them in 50\% hexamethyldisilazine (HMDS) for $2 \mathrm{~h}$ and then in pure HMDS for $8 \mathrm{~h}$ which was then allowed to evaporate. Specimens were mounted on an aluminium stub, exposed for $2 \mathrm{~h}$ to osmium tetroxide vapour, sputter coated with gold and examined with a JEOL 6300 Field Emission SEM operating between 5 and $7 \mathrm{kV}$.

Preserved adult specimens were examined using a compound photomicroscope equipped with phase contrast optics and drawings were made with the aid of a drawing tube. Measurements were made using a computerised digitising system similar to that described by Roff and Hopcroft (1986). All measurements are given in micrometres as the mean followed in parentheses by the range and the number of structures measured. Haptoral terminology follows that of Chisholm et al. (1995).

Type material of Heliocotyle kartasi (No. 1998.1.16. 1-3) from The Natural History Museum BM(NH), Cromwell Road, London, SW7 5BD, UK was examined for comparative purposes. Type material of $H$. ewingi is deposited in The Queensland Museum (QM), P.O. Box 3300, South Brisbane, Queensland 4101, Australia and at the Institute of Parasitology (IPCR), Academy of Sciences of the Czech Republic, Branišovská 31, 37005 České Budějovice, Czech Republic.

\section{RESULTS}

$\mathrm{H}$ e t e r o c o t y 1 i n a e Chisholm, Wheeler et Beverley-Burton, 1995

Heliocotyle Neifar, Euzet et Ben Hassine, 1999

Amended generic diagnosis. Heterocotylinae (sensu Chisholm and Whittington 1996). Haptor with one central and seven peripheral loculi. Marginal valve 
present. Hamulus located in posterolateral septum; handle and guard well developed. Septal ridge present; not sinuous in $H$. kartasi; sinuous on inner ring septum and slightly sinuous on radial septa of $H$. ewingi. Pseudosepta present on all loculi except posteriormost; single (H. ewingi) or three pseudosepta present in posterolateral and anterior loculi and four present in anterolateral loculi (H. kartasi). Single semicircular dorsal haptoral accessory structure associated with posterior loculus. Eyespots present or absent. Two intestinal caeca without diverticula; not confluent posteriorly. Testis single. Male copulatory organ sclerotised; spiral or straight; sclerotised sleeve present or absent. Vaginal pore unarmed, sinistroventral; vagina walls unsclerotised. Gill parasites of Myliobatididae.

T y p e s p e c i e s : Heliocotyle kartasi Neifar, Euzet et Ben Hassine, 1999 from Pteromylaeus bovinus.

A d d i t i o n a 1 s p e c i e s: Heliocotyle ewingi sp. n. from Myliobatis australis.

\section{Heliocotyle ewingi sp. n.}

Figs. 1-3

Description. (Description and measurements based on 23 flattened specimens): Body (excluding haptor) 477 (335-686, $\mathrm{n}=21)$ long, $235(149-279, \mathrm{n}=21)$ wide at level of ovary. Haptor transversely oval, 216 (179$244, \mathrm{n}=16)$ long, $263(224-291, \mathrm{n}=16)$ wide. Single pseudoseptum on all loculi except posteriormost (Figs. 1, 3A). Septal ridge sinuous on inner ring septum, slightly sinuous on radial septa and not sinuous on outer ring septum (Figs. 1A, 3A, B); could not determine if ridge sclerotised. Semicircular haptoral accessory structure associated with dorsal surface of posteriormost loculus (Figs. 1, 3C). Hamulus $43(40-47, \mathrm{n}=14)$ long with well developed handle and guard (Fig. 2A). Hooklets 14, $9(8-11, \mathrm{n}=14)$ long, distributed on marginal valve of haptor as illustrated (Fig. 1).

Two ducts from anteromedian gland, one duct from each anterolateral gland all containing granular secretion run to anterior end (Fig. 1). Additional gland duct endings with granular secretion observed along ventrolateral margin of head (Fig. 1) but ducts from these endings could not be traced to either anteromedian or anterolateral glands. Three fine gland duct endings containing needle-like secretion open into single aperture on ventrolateral surface on either side of head (Figs. 1, 3D); glands and ducts associated with these apertures not seen. Pharynx $74(62-83, \mathrm{n}=23)$ long, 61 $(49-68, \mathrm{n}=23)$ wide; pharyngeal glands not observed. Oesophagus absent. Dispersed pigment granules (eyespots) prominent anterodorsal to pharynx (Fig. 1). Glands in posterior part of body present in some other heterocotylines not seen.

Testis single (Fig. 1). Vas deferens arises from left side of testis, runs anteriorly dorsal to vagina and transverse vitelline duct; inflates to form coiled seminal

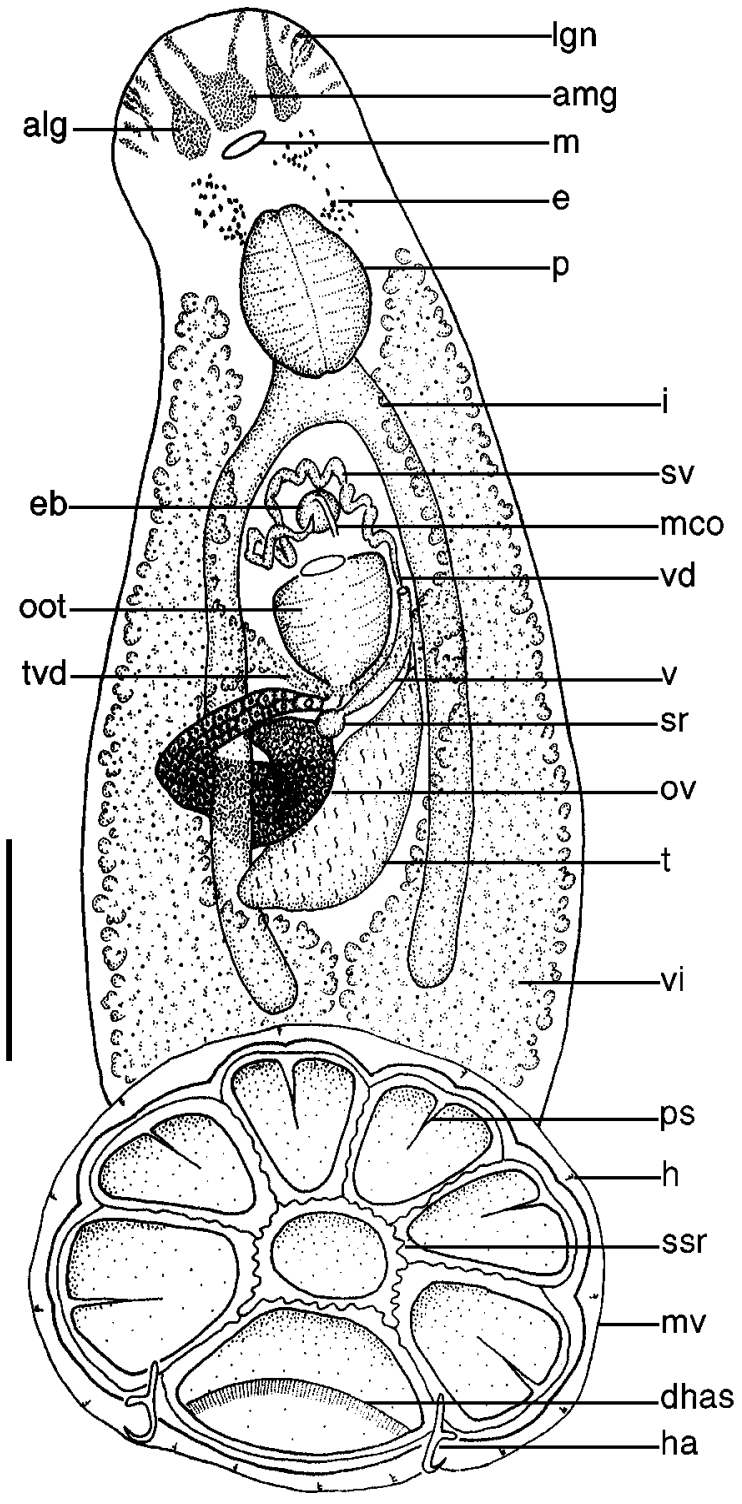

Fig. 1. Heliocotyle ewingi sp. n. Full-body drawing, ventral view. Abbreviations: alg - anterolateral gland with granular secretion; amg - anteromedian gland with granular secretion; dhas - dorsal haptoral accessory structure; e - eyespots; eb ejaculatory bulb; $\mathrm{h}$ - hooklet; ha - hamulus; $\mathrm{i}$ - intestinal caecum; lgn - lateral gland duct endings with needle-like secretion; $\mathrm{m}$ - mouth; mco - male copulatory organ; mv marginal valve; oot - oötype; ov - ovary; $\mathrm{p}$ - pharynx; ps pseudoseptum; sr - seminal receptacle; ssr - sinuous septal ridge; $\mathrm{sv}$ - seminal vesicle; $\mathrm{t}$ - testis; tvd - transverse vitelline duct; v - vagina; vd - vas deferens; vi - vitellarium. Scale bar $=100 \mu \mathrm{m}$.

vesicle, curves to right side of body anterior to ejaculatory bulb, runs posteriorly looping and narrowing, to enter posterior part of ejaculatory bulb (Fig. 1). Ejaculatory bulb small, $19(16-22, \mathrm{n}=17)$ long, 18 $(14-20, n=17)$ wide. Male accessory glands not seen. 

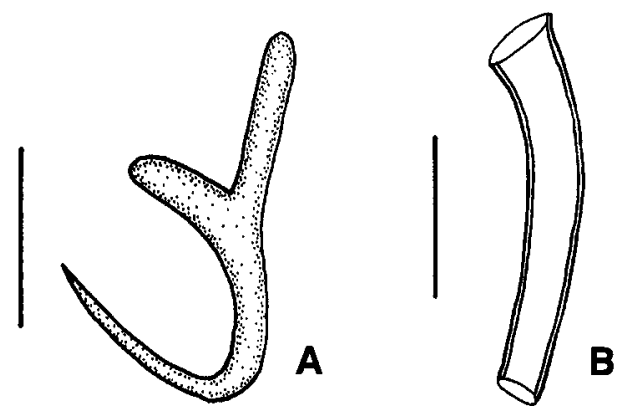

Fig. 2. Heliocotyle ewingi sp. n. A - hamulus. B - male copulatory organ. Scale bars: $A=20 \mu \mathrm{m} ; \mathrm{B}=10 \mu \mathrm{m}$.

Male copulatory organ short, relatively straight sclerotised tube 23 (20-26, $\mathrm{n}=13)$ long (Figs. 1, 2B). Accessory piece or sleeve absent.

Ovary loops right intestinal caecum dorsoventrally, narrows to form oviduct (Fig. 1). Oviduct becomes ovovitelline duct, runs anteriorly to join oötype. Oötype $56(43-67, \mathrm{n}=18)$ long. Mehlis' glands not observed. Vaginal pore, unarmed, sinistroventral at level posterior to common genital pore. Walls of vagina not sclerotised; leading to small seminal receptacle 18 (14$23, \mathrm{n}=10$ ) diameter. Vitellarium extending from level of mid-part of pharynx to posterior portion of body proper. Transverse vitelline duct at level just anterior to ovary; common vitelline duct enters oviduct dorsally. Egg tetrahedral.

$\mathrm{T}$ y $\mathrm{p}$ e h o s t : Myliobatis australis Macleay, 1881 (Myliobatididae).

T y p e 1 o c a 1 i t y : Norfolk Bay, Tasmania, Australia $\left(23^{\circ} 27^{\prime} \mathrm{S}, 151^{\circ} 55^{\prime} \mathrm{E}\right)$.

M i c r o h a b i t a t : Parasites between secondary lamellae of gills. Usually found in pairs separated by 7-10 secondary lamellae.

I $\mathrm{n} \mathrm{fe} \mathrm{c} \mathrm{t} \mathrm{i} \mathrm{o} \mathrm{n} \mathrm{d} \mathrm{e} \mathrm{t} \mathrm{a} \mathrm{i} 1 \mathrm{~s}$ : One ray infected with 64 monocotylids.

E t y m o lo g y : This species is named after Graeme Ewing from the Tasmanian Aquaculture and Fisheries Institute who kindly collected the ray for us.

T y p e m a t e r i a 1: Holotype QM G 217429, 20 paratypes QM G 217430-49; 2 paratypes IPCR M-357.

Remarks. Heliocotyle ewingi can be distinguished readily from $H$. kartasi by the haptor which has a single pseudoseptum on each of the loculi except the posteriormost and by the male copulatory organ which is a short, relatively straight sclerotised tube without an accessory piece or sleeve. Furthermore, eyespots, which are apparently absent in $H$. kartasi, are present in $H$. ewingi.

\section{DISCUSSION}

Heliocotyle ewingi has a single semicircular accessory structure on the dorsal surface of the haptor which places it in Heliocotyle but we have amended the diagnosis of Neifar et al. (1999) to accommodate it further. The number of pseudosepta is variable in the genus. In $H$. ewingi, a single pseudoseptum is present on all the peripheral loculi except the posteriormost whereas $H$. kartasi has three pseudosepta on the posterolateral and anterior loculi and four on the anterolateral loculi. Pseudosepta have also been described in Troglocephalus rhinobatidis Young, 1967 (see Young 1967). The form of the septal ridge is also variable (see below). Eyespots which are absent in $H$. kartasi are present in $H$. ewingi but their presence or absence is not unique to Heliocotyle because eyespots are also either present or absent in species of Empruthotrema Johnston et Tiegs, 1922 (see Chisholm and Whittington 1999). Neifar et al. (1999) describe the male copulatory organ of $H$. kartasi with a "sclerotised sleeve" (as apposed to an "accessory piece"). The male copulatory organ of $H$. ewingi does not have an additional sclerotised structure of any kind associated with it.

The anterior end of Heliocotyle species is complicated and deserves further study. These are extremely small worms and it is difficult to determine the nature of the anterior glands and their associated ducts and openings in fixed material. An anteromedian gland and a pair anterolateral glands which contain granular secretion are present in both species of Heliocotyle. This is similar to the arrangement of anterior granular glands reported in species of Heterocotyle Scott, 1904 (see Chisholm and Whittington 1996) and Decacotyle Young, 1967 (see Chisholm and Whittington 1998). Two ducts lead from the anteromedian gland and appear to open on the anterior margin of the head. However, we could not find these duct openings in $H$. ewingi using SEM (see Fig. 3D). Neifar et al. (1999) illustrate numerous gland ducts arising from the anterolateral glands of $H$. kartasi. This arrangement is different from Heterocotyle and Decacotyle where only a single gland duct arises from each anterolateral gland and opens on the anterolateral margin of the head (see Chisholm and Whittington 1996, 1998, respectively). The numerous ducts from the anterolateral glands of Heliocotyle kartasi do not open on the margin of the head but instead appear to terminate short of the edge. In $H$. ewingi we also found numerous gland duct endings but we could only trace the anteriormost pair of ducts from the anterolateral glands (see Fig. 1). We could not determine if the additional gland duct endings seen along the inner margin of the head arose from the anterolateral glands as is described for H. kartasi (see 

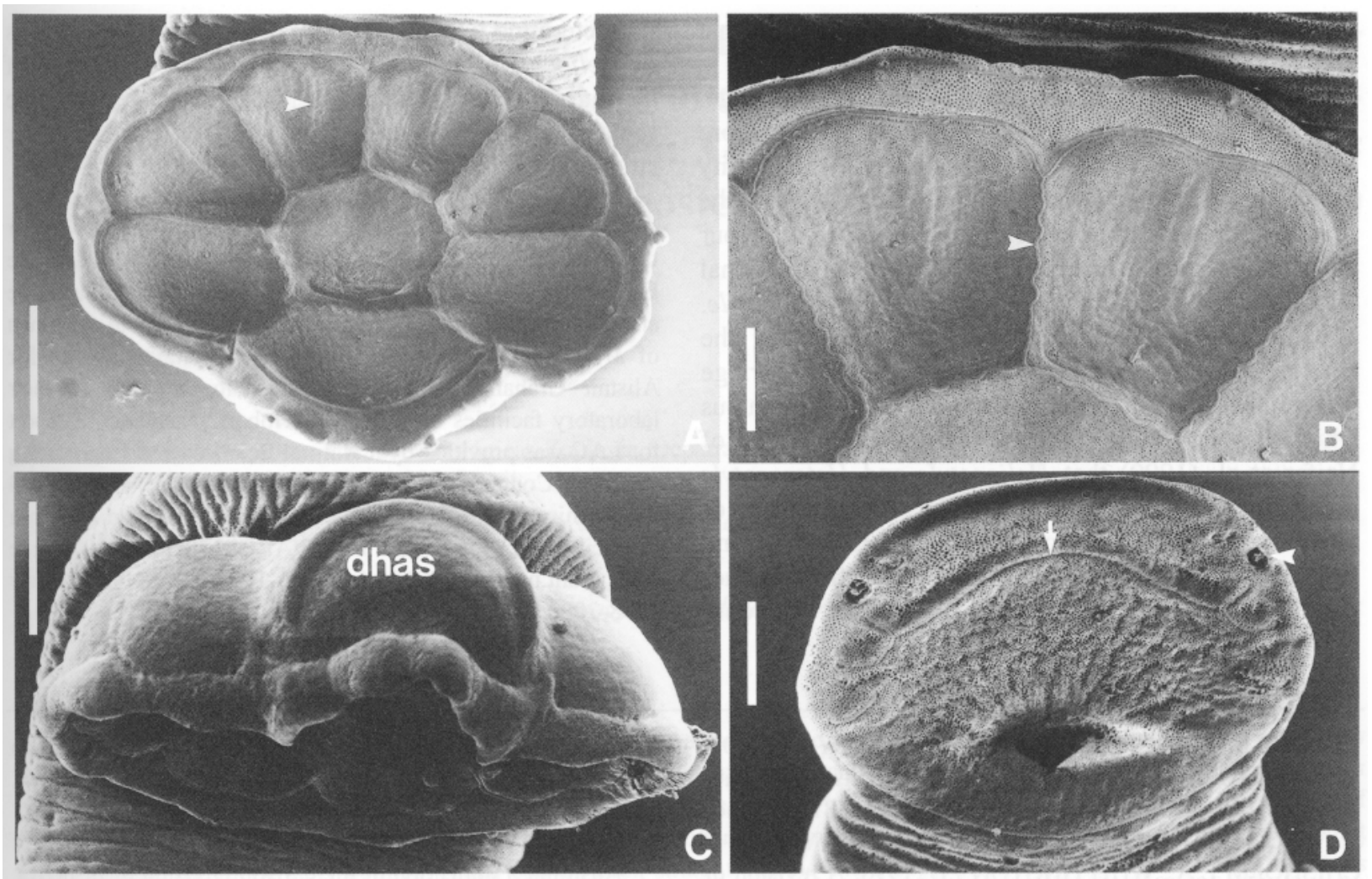

Fig. 3. Scanning electron micrographs of Heliocotyle ewingi sp. n. A - ventral surface of haptor showing the peripheral loculi with pseudosepta (arrowhead) and the septal ridge which is sinuous on the inner ring septum and the peripheral septa; $\mathbf{B}$ magnified view of anterior loculi showing sinuous septal ridge (arrowhead); $\mathbf{C}$ - dorsal surface of haptor with dorsal haptoral accessory structure (dhas); D - ventral surface of anterior end showing single prominent anterior gland duct opening (arrowhead) on either side of head and distinct ridge of tissue (arrow). Scale bars: $\mathrm{A}, \mathrm{C}=50 \mu \mathrm{m} ; \mathrm{B}, \mathrm{D}=20 \mu \mathrm{m}$.

Neifar et al. 1999). Again, SEM could not confirm the presence of pores on either the dorsal or ventral surface of the anterior end of $H$. ewingi which may be associated with these granular gland duct endings. What SEM did reveal, however, was a single distinct gland duct opening on either side of the ventral surface of the head (Fig. 3D). These appear to be the pores into which the three swollen gland duct endings (with needle-like secretion) on each side of the anterior end open (see Fig. 1). Unfortunately, we could not find the glands from which these needle-like secretions arise. Neifar et al. (1999) also describe the presence of three needle-like gland duct endings in $H$. kartasi but again they could not trace their origin. In Heterocotyle and Decacotyle the glands which contain needle-like secretion are located lateral to the pharynx (see Chisholm and Whittington 1996, 1998). Neifar et al. (1999) describe six "ventral depressions" (three on each side) on the anterior end of Heliocotyle kartasi but we did not observe these using either light microscopy or SEM in $H$. ewingi. A ridge (muscular?) with a distinct branching pattern is visible on the ventral surface of the head of $H$. ewingi using SEM (Fig. 3D). A ridge is also illustrated in $H$. kartasi (see Neifar et al. 1999) although it is not described. Could the granular gland duct endings which do not terminate at the margin of the head be associated with the branches of this ridge (see Fig. 3D)? Are the depressions described by Neifar et al. (1999) merely an artefact of this ridge? Clearly, the arrangement of the anterior glands, ducts and openings, the presence of the depressions and the nature of the anterior ridge in Heliocotyle spp. still need to be resolved by examination of live material, SEM and transmission electron microscopy.

Neifar et al. (1999) placed Heliocotyle in the Heterocotylinae because of the single semicircular accessory structure on the dorsal surface of the haptor. They remarked that the Heterocotylinae could be divided into two groups: one comprising Heterocotyle with four dorsal haptoral sclerotised structures and the other comprising Neoheterocotyle Hargis, 1955, Nonacotyle Ogawa, 1991, Potamotrygonocotyle Mayes, Brooks et Thorson, 1981 and Spinuris Doran, 1953 which all have more than six dorsal haptoral sclerotised structures. Neifar et al. (1999) stated further that Heliocotyle did not fit into either of these groups, in 
part, because there was no sinuous septal ridge. However, they believed that Heliocotyle was more closely related to Heterocotyle because of the similarity in the dome-shaped dorsal haptoral structures and the presence of an additional ridge adjacent to the four anteriormost septa which is reminiscent of the additional sinuous ridge found in some species of Heterocotyle. We did not find an additional ridge underlying the anterior septa of Heliocotyle ewingi but the septal ridge on the inner ring and radial septa of $H$. ewingi is sinuous which may lend further support for the presumption of Neifar et al. (1999) that Heliocotyle and Heterocotyle are closely related. However, the septal ridge of Heterocotyle is clearly sclerotised (see Chisholm and Whittington 1996). Neifar et al. (1999) question whether the septal ridge in $H$. kartasi is sclerotised. We could not determine whether the septal ridge in either species of Heliocotyle is sclerotised or simply a thickening of the muscular septum and therefore it is possible that the septal ridges in Heterocotyle and Heliocotyle differ structurally.

Acknowledgements. We thank Dr David Gibson BM(NH) for the loan of type material. We are indebted to Mr Graeme Ewing and Dr Alan Jordan from the Tasmanian Aquaculture and Fisheries Institute (Taroona) for collecting the specimen of Myliobatis australis and for their hospitality and to $\mathrm{Mr}$ Alistair Graham and Dr Peter Last for the use of their laboratory facilities at CSIRO in Hobart, Tasmania. Support for LAC was provided by a Natural Sciences and Engineering Research Council of Canada Postgraduate and Postdoctoral Fellowship. Support for IDW came from Australian Research Council (ARC) small grant no. 97/ARCS150G for 1997, large ARC grant no. A19600180 for 1996-1998 and A19801424 for 1998-2000.

\section{REFERENCES}

CHISHOLM L.A., WHEELER T.A., BEVERLEY-BURTON M. 1995: A phylogenetic analysis and revised classification of the Monocotylidae Taschenberg, 1879 (Monogenea). Syst. Parasitol. 32: 159-191.

CHISHOLM L.A., WHITTINGTON I.D. 1996: A revision of Heterocotyle (Monogenea: Monocotylidae) with a description of Heterocotyle capricornensis n. sp. from Himantura fai (Dasyatididae) from Heron Island, Great Barrier Reef, Australia. Int. J. Parasitol. 26: 1169-1190.

CHISHOLM L.A., WHITTINGTON I.D. 1998: Revision of Decacotylinae Chisholm, Wheeler \& Beverley-Burton, 1995 (Monogenea: Monocotylidae) including the synonymy of Papillicotyle Young, 1967 with Decacotyle Young, 1967 and a description of Decacotyle tetrakordyle n. sp. from Pastinachus sephen (Forsskål) (Myliobatiformes: Dasyatididae) from Australia. Syst. Parasitol. 41: 9-20.

CHISHOLM L.A., WHITTINGTON I.D. 1999: Empruthotrema quindecima sp. n. (Monogenea: Monocotylidae) from the nasal fossae of Taeniura lymma (Dasyatididae) from Heron Island and Lizard Island, Great Barrier Reef, Queensland, Australia. Folia Parasitol. 46: 274-278.

LAST P.R., STEVENS J.D. 1994: Sharks and Rays of Australia. Publication of the CSIRO Division of Fisheries, Australia, $513 \mathrm{pp}$.

NEIFAR L., EUZET L., BEN HASSINE O.K. 1999: Heliocotyle kartasi gen. et sp. n. (Monogenea: Mono-cotylidae) parasitic on Pteromylaeus bovinus (Euselachii: Myliobatinae) from Tunisia. Folia Parasitol. 46: 29-32.

ROFF J.C., HOPCROFT R.R. 1986: High precision microcomputer based measuring system for ecological research. Can. J. Fish. Aquat. Sci. 43: 2044-2048.

YOUNG P.C. 1967: A taxonomic revision of the subfamilies Monocotylinae Gamble, 1896 and Dendromonocotylinae Hargis, 1955 (Monogenoidea: Monocotylidae). J. Zool. (Lond.) 153: 381-422.

Accepted 21 October 1999 